Original Research Article

\title{
Adverse drug reaction monitoring of antitubercular drugs at tertiary care medical college hospital: prospective study
}

\author{
Shubha Revanna ${ }^{1}$, Chinmayi Kaggere Harish ${ }^{2 *}$, Gramle Amol ${ }^{1}$
}

\begin{abstract}
${ }^{1}$ Department of Pharmacology, ${ }^{2}$ Student, Sapthagiri Institute of Medical Science and Research Centre, Bangalore, Karnataka, India
\end{abstract}

Received: 15 May 2017

Revised: 23 September 2017

Accepted: 27 September 2017

\section{*Correspondence to:}

Chinmayi Kaggere Harish, Email: chinmayiharish060@ gmail.com

Copyright: (C) the author(s), publisher and licensee Medip Academy. This is an openaccess article distributed under the terms of the Creative Commons Attribution NonCommercial License, which permits unrestricted noncommercial use, distribution, and reproduction in any medium, provided the original work is properly cited.

\begin{abstract}
Background: To study the socio-demographic profile of patients receiving DOTS and to estimate the prevalence of adverse drug reaction and casualty in patients receiving DOTS.

Methods: This is a self reporting prospective study, trained personnel instructed patients about treatment and possible adverse drug reaction and patient telephone number was noted and pamphlet with information about possible ADR'S and containing contact number of the staff in-charge was distributed among the patients and they were instructed to contact staff if any mild or severe ADR'S was noticed and also staff in-charge himself contacted patients regularly for update of neglected ADR'S and noted information was tabulated ,analyzed using and frequency table with percentage and chi-square test of significance was calculated and causality was assessed using Noranjo scale and severity using modified Hartwig and Siegal scale.
\end{abstract}

Results: The commonest ADRs received were gastritis in 32 (20\%) patients, followed by myalgia in $25(15.6 \%)$ and fatigue in 21(13.12\%) patients. Major adverse events included chest pain, joint pain, edema, blurring of vision and mental depression. It was surprising that none of the patients reported with any untoward skin reactions. In a small sample of 64 subjects, 160 ADRs were noted and among the ADRs there by received, the statistically significant value obtained was only with that of gastritis $(\mathrm{p}=0.025)$.

Conclusions: Incidence of fatal ADR's in DOTS is none with extremely low incidence of severe ADR's with only mild to moderate ADR'S reported DOTS is relatively safe in treatment of tuberculosis.

Keywords: Adverse drug reaction monitoring study, Antitubercular drug treatment, Adverse drug reaction in DOTS treatment, DOTS study, Pharmacovigilance

\section{INTRODUCTION}

WHO defines 'pharmacovigilance' as the science and activities relating to the detection, assessment, understanding and prevention of adverse effects or any other drug related problems. ${ }^{1}$ Thalidomide disaster in 1961 was the landmark for establishment of the international drug monitoring programme. ${ }^{2}$ The safety profile of drugs is dynamic; new information is continuously assessed regarding use and outcomes. ${ }^{3}$ WHO Pharmacovigilance programme of India was started with the aim of generating the database among Indian population. ${ }^{4}$ Adverse drug reactions (ADRs) are one of the leading causes for mortality and morbidity worldwide. ${ }^{5}$ Which can also lead to the financial burden to the patients along with the treatment costs and on cost of healthcare delivery of the nation.

According to WHO, Tuberculosis is an infective bacterial disease caused by mycobacterium tuberculosis, which most commonly affects the lungs. 11,83,371 new cases have been detected in India in the year $2012 .{ }^{6}$ Treatment 
of tuberculosis has become a challenge due many reasons. Firstly, the cell wall of tubercle bacilli is composed of mycolic acids with many chains made of 76-90 carbon atoms. This protective shield prevents anti tubercular drug from entering into the cytosol. Efflux pumps present on cell membrane prevent anti tubercular drugs from entering. Another barrier is that some bacilli are also intracellularly located, which makes it even more difficult to treat. Ability of tubercle bacilli to acquire resistance to ATT is very high. ATT have high range of adverse effects. Hence to decrease the resistance and adverse drug reactions, combination of drugs is used. Hence, these drugs are expected to cause adverse drug reaction. ${ }^{7}$

RNTCP (Revised National Tuberculosis Control programme) is a mega national program started in 1997 in India. Around 3,500 patients are initiated with treatment at DOTS centre per day in India. DOTS program is a boon to the tuberculosis patients, consisting of a combination of many drugs. ${ }^{8}$ Treatment phase has been classified into intensive phase which lasts for period of 2-3 month. This phase is aimed to kill the bacteria rapidly and decrease the chance of acquiring resistance. This will lead to sputum conversion and symptomatic relief. Next phase is continuous phase lasting for 4-5 months, which is aimed at eliminating the remaining bacteria and to prevent relapse. ${ }^{9}$

As many new drugs are being introduced in treatment, newer, rare and unreported adverse reactions are also expected. ${ }^{10}$ Severe adverse drug reactions can lead to discontinuation of treatment abruptly and lead to relapse or multi drug resistance. Hence monitoring of these related ADRs is very essential wherein the drug causing ADR can be detected and appropriate therapeutic regimen can be tailored to the patient. Therefore, Pharmacovigilance of anti tubercular drugs is very much essential for successful treatment story of tuberculosis and its elimination.

\section{The fight against TB in India: the journey so far}

Since the beginning of the twentieth century, India has been in the forefront of TB research and control. The National Tuberculosis Control Program was launched in 1962, but it suffered from inadequate funding, lacunae in management, irregular and errant drug supply and multiple or combination treatment regimens. Then the Revised National Tuberculosis Control Program was piloted in 1993 and was based on DOTS. DOTS, which was the internationally recommended strategy for TB control promoted diagnosis by sputum smear microscopy, direct observation of treatment, standardized regimens, recording and reporting of notified cases and treatment outcomes. A greater degree of public and political commitment is required in the effective management of the disease.

In India, Tuberculosis is a disease which is strongly associated with poverty and deprivation. TB patients encounter innumerable constraints in getting proper treatment and adhering to it. Many studies have shown various reasons for default such as inconvenience of clinic timings resulting in loss of wages, cost of travel to the clinic, lack of provision for continuity of treatment in case of a family emergency resulting in a missed visit to the clinic, poor management of adverse events and toxicity.

Therefore, despite the availability of effective chemotherapy, TB is still a major health problem is many countries. This can be attributed to poor patient compliance, to primary multidrug resistance and to interruption partly due to adverse drug reactions.

The standard anti-TB short course chemotherapy is the key component of the DOTS strategy. This requires continually taking drug combinations of different antitubercular drugs every alternative day for a prolonged period of time. It is currently used in majority of the countries with higher TB burden.

These drugs, in addition to their role in destroying and inhibiting Mycobacterium tuberculae, also cause different kinds of adverse drug reactions involving almost all systems in the body including the gastrointestinal system, liver, skin, nervous system, otovestibular apparatus and eyes. ADR of one drug may be potentiated by a companion drug. These Adverse drug reactions are the major cause of noncompliance to antitubercular treatment.

The present study was conducted with the following primary objectives:

- To study the socio-demographic profile of patients receiving DOTS.

- To assess the rate of prevalence of ADRs with antitubercular drugs.

- To assess the causality using Naranjo Scale and severity using modified Hartwig and Siegel scale.

\section{METHODS}

This study was a prospective, self reporting study which was conducted at a tertiary care medical college hospital in collaboration with Pulmonology Department at Sapthagiri Institute of Medical Science and Research Center, Bangalore, Karnataka. The study was carried out after obtaining permission from the Institutional ethical committee for a stipulated period of 02 months between $1 / 05 / 2014$ to $30 / 06 / 2014$.

Trained personnel instructed the patients to follow the process and patient's telephone numbers were noted. A pamphlet with information to be noted by patients was distributed. This patient information pamphlet was validated by the physician, pulmonologist and pharmacologist. Information regarding disease process, possibility of adverse drug reactions, patient responsibility (to inform ADRs to doctor), contact numbers of the staff in charge were provided in the pamphlet which was bilingual (English and Kannada). Those who did not know these two languages were provided with pamphlet in 
Hindi. Content of the pamphlet was also explained to the patients in their own vernacular language. Patients were asked to contact the in- charge person immediately when any mild/sever ADR was noticed. Patients were regularly contacted and any missed /neglected ADRs were noted down.

\section{Inclusion criteria}

All patients of either sex visiting tertiary care hospital, new or old cases, all types of tuberculosis patients in Phase I and Phase II.

\section{Exclusion criteria}

Patients with co-morbid medical or surgical conditions were excluded except HIV infection.

Common ADRs to be noted by patients were nausea, vomiting, joint pain, skin rash/itch, headache, chest pain, dysurea, abdominal pain, back pain, body pain, anorexia, tiredness, diarrhea, weight loss, giddiness, visual problems, pedal edema, and elevated liver enzymes.

\section{RESULTS}

Adverse drug reactions due to ATT are expected to be present in a majority of the patients as part of the multi drug combinations or due to the disease process.

During the study, the self reporting due to the dissemination of information through patient education pamphlets was studied in the medical college hospital in conjunction with the Pulmonology Department and also with the validated reporting forms.

- A total of 64 patients were incorporated in the study. All the patients received the ATT and none defaulted. All the patients taking DOTs in chikkabanavara and hesaraghatta PHC were enrolled in study.

- Regular telephone calls were made enquiring about adverse effects. Once the patient complained about any ADR, immediately he/she was contacted, history taken, ADR noted and the ADR form was filled and an attempt to determine the causality and severity was undertaken.

- Statistical analysis was done with the SPSS software version 16. Wherever applicable, the chi square test of significance was applied.

- The socio-demographic profiles of the patients are depicted in the Figure 1. Of the 64 patients taking the ATT, 43 (67.19\%) were males and $21(32.81 \%)$ were females. Therefore, the sample size included more of the males than the females. Many studies.

According to RNTCP status report (TB India 2006) TB affects habitually in young adults with an age range of ' 25 34'. In our study maximum patients belonged to the age range of 21-40 years.

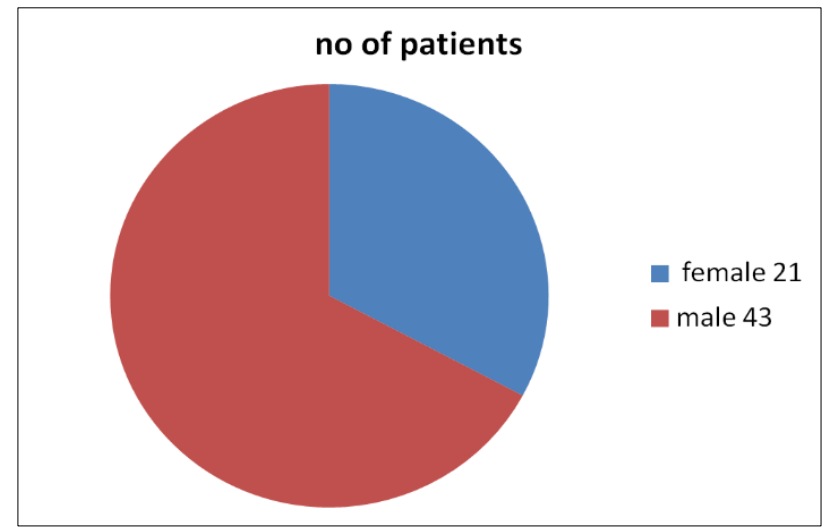

Figure 1: Socio demographic profile of the patients.

Table 1: Incidence of tuberculosis according to age, sex and body weight.

\begin{tabular}{|c|c|c|c|}
\hline $\begin{array}{l}\text { Basic } \\
\text { parameter }\end{array}$ & & Frequency & Percentage \\
\hline \multirow{6}{*}{$\begin{array}{l}\text { Age in } \\
\text { years }\end{array}$} & $<20$ years & 6 & 3.8 \\
\hline & $21-30$ years & 12 & 7.2 \\
\hline & $31-40$ years & 15 & 9.5 \\
\hline & $41-50$ years & 17 & 9.8 \\
\hline & $51-60$ years & 6 & 3.8 \\
\hline & $>60$ years & 8 & 4 \\
\hline \multirow{2}{*}{ Sex } & Male & 43 & 67.19 \\
\hline & Female & 21 & 32.81 \\
\hline \multirow{5}{*}{$\begin{array}{l}\text { Body } \\
\text { weight in } \\
\text { Kgs }\end{array}$} & $<35$ & 3 & 4.68 \\
\hline & $36-45$ & 32 & 50 \\
\hline & $46-55$ & 21 & 32.81 \\
\hline & $55-65$ & 6 & 10 \\
\hline & $>65$ & 2 & 3.12 \\
\hline
\end{tabular}

The Disease characterization into pulmonary and extra pulmonary was also done (Figure 2) Pulmonary tuberculosis was found to be present in $44(68.75 \%)$ and extra pulmonary tuberculosis in $20(31.25 \%)$ patients.

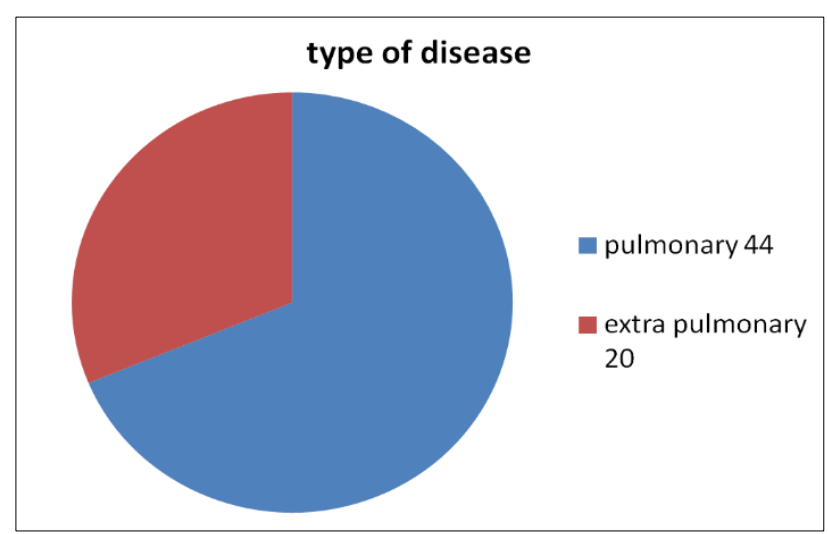

Figure 2: Type of disease.

Six patients during the study period decided to obtain medications through private procurement. They objected 
to receive the DOTS for various reasons which included maintenance of confidentiality, concern over the quality of the medications provided under the RNTCP among others. However, they were also adequately sensitized on self reporting through telephonic call. Patient education pamphlets were also provided to them. The pharmacovigilance activities pertaining to ADR was also perceived to be picked up in these groups of patients.

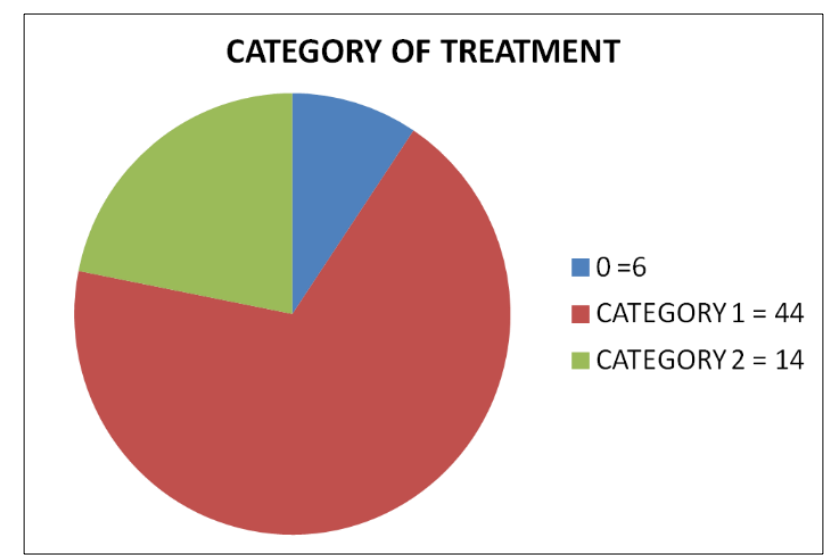

0: For private medications

Category 1: new case

Category 2: relapse cases

Figure 3: Pts on different categories of treatment.

The treatment characterization into the intensive phase and continuation phase was also done as per the Figure 4.

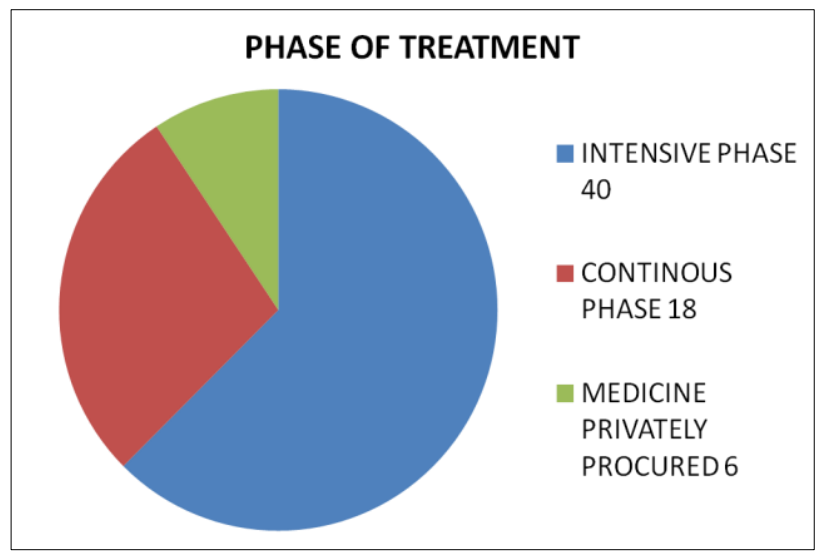

Figure 4: Phase of treatment.

This study was conducted with regard to receiving even the trivial ADRs. Patient compliance was placed a special emphasis. It was surprising to note that all the 64 patients developed ADRs due to ATT, which ranged from trivial to certain rare ADRs in a small sample size. The major intention of the study was to document even the mildest of the adverse drug reactions. The ADRs received are mentioned in the Figure. The commonest ADRs received were gastritis in $32(20 \%)$ patients, followed by myalgia in $25(15.6 \%)$ and fatigue in $21(13.12 \%)$ patients. Major adverse events included chest pain, joint pain, edema, blurring of vision and mental depression. It was surprising that none of the patients reported with any untoward skin reactions. In a small sample of 64 subjects, 160 ADRs were noted and among the ADRs there by received, the statistically significant value obtained was only with that of gastritis $(p=0.025)$. However, many of the ADRs were present with a combination and not in isolation. A major deviant trend was thus noted compared to the other studies. It was found that acneiform drug eruptions were common with respect to the ATTs. But no such reactions were documented in our study as only skin rashes were seen.

\section{Causality assessment}

As per Naranjo algorithm 93 (58.7\%) ADRs were possible, $5(3.12 \%)$. ADRs were unlikely and $62(38.75 \%)$ were probable. Since combinations of drugs are used, it was difficult to assess the actual causality.

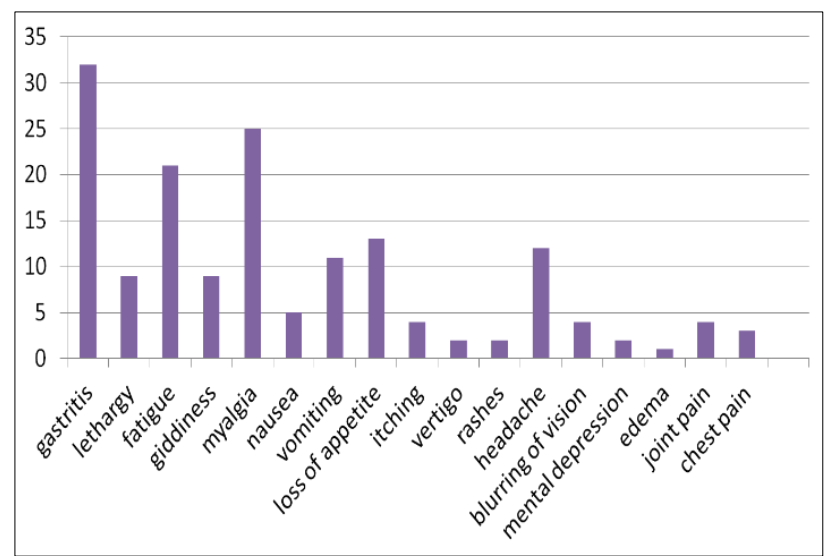

Figure 5: Types of adverse reactions.

\section{Severity assessment}

- $\quad 125(78.12 \%)$ of the cases were mild (level-1)

- $20(12.5 \%)$ were moderate (level 2)

- $15(9.3 \%)$ were severe (level 3)

- $0 \%$ was lethal (level 4)

According to the Modified Hartwig and siegel scale, Gastritis, lethargy, fatigue, giddiness, nausea, myalgia, vomiting was considered as mild cases, itching, loss of appetite, vertigo and rashes were considered as moderate and blurring of vision, mental depression, edema, joint pain and chest pain under the severe cases.

\section{DISCUSSION}

64 patients were included in the study. It was surprising to note that all the 64 patients recfeiving DOTS therapy during the study period experienced ADRs which is entirely different from the study conducted by Mishin et al. ${ }^{11}$

The results obtained were an attempt to detect, assess, classify and document the ADRs due to ATT. An attempt to stratify the case through severity and document the case 
with the causality assessment was also done. It was found as per the study, a large number of ADRs that are often missed can be documented by enquiring through a telephonic conversation. The commonest ADRs received were gastritis $32(20 \%)$ followed by myalgia $25(15.6 \%)$ and fatigue $21(13.12 \%)$.

In our study, common ADRs were related to GIT system that is gastritis. This can be attributed to multi drug therapy by oral route. This is similar to the study conducted by Dhingra et al. ${ }^{12}$

In a study conducted by Anupa Khatri Chhetri et al, the incidence of ADRs with only INH reported was $49.3 \%$ while it was not possible to exactly document with a single drug in our study. ${ }^{13}$ However, as per the causality in our study it was found that $58.7 \%$ of the ADRs were possible. Since, the maximum ADRs were from the patients receiving the intensive phase of the treatment wherein, Isoniazid is used, we can attribute these ADRs to the same.

In a study conducted by Hema N G et al, $8.3 \%$ of the cases were found to be HIV positive. ${ }^{14}$ Whereas, there were no patients with concurrent HIV infection in our study. This could be possible due to a small sample size.

It was found that despite effective sensitization through patient information leaflets, the self reporting was dismally low. Only 5 patients $(7.8 \%)$ who received ATT contacted the study personnel. It was concluded that even after repeated efforts by the study personnel, self reporting was not up to the expectations.

Since the study period was limited for only two months, the sample size was small to properly arrive to a conclusion. Laboratory investigations re-challenge and drug withdrawal tests could not be done due to ethical concerns.

\section{CONCLUSION}

It was very difficult to attribute ADRs to a single drug due to the small sample size. It was also noted that even with our best efforts, self reporting was not up to the expectations. So, a sincere effort from patients is very much required to make RNTCP and National Pharmacovigilance Programme successful.

Funding: No funding sources

Conflict of interest: None declared

Ethical approval: The study was approved by the Institutional Ethics Committee

\section{REFERENCES}

1. Sachdev Y. Status of adverse drug reaction monitoring and pharmacovigilance in selected countries. Indian J Pharmacol. 2008;40:4-9.

2. Dave VS. Current Trends in Pharmacovigilance. J Pharmacovigilance. 2013;1:e104.
3. Generali JA. Adverse Drug Event Reporting: Awareness Is Not Enough. Hosp Pharm. 2014;49:11011.

4. Nagpure S, Kale R, Varma S, Bahekar S. Impact on educational intervention on knowledge, attitude and practice of Pharmacovigilance among medical graduates of rural tertiary care, teaching hospital of central India. Mintage Journal of pharmaceutical and medical science. 2013;2(3):51-4.

5. Palaniswamy S, Arul Kumaran KSG, Rajasekharan A. A study of assessment, monitoring and reporting of adverse drug reactions in Indian hospital. Asian $\mathbf{J}$ Pharm Clin Res. 2011;4(3):112-6.

6. Pharmacovigilance in tuberculosis care. Available at: www.who.int/tb/. Accessed on January 21,2014.

7. Goodman and Gilman's. The pharmacological basis of therapeutics. $12^{\text {th }}$ Edition; 2011:1549.

8. Revised National TB Control Program. TB India; Annual status report. Central TB division, Directorate General of Health and Family Welfare, Nirman Bhavan, New Delhi, 2011. Available at: http://planningcommission.nic.in/reports/genrep/healt h/RNTCP_20 11.pdf Accessed on January 20,2014.

9. Revised National TB Control Programme. DOTS plus guidelines. January 2012. Available at: http://www.tbcindia.nic.in/pdfs/DOTS_Plus_Guidrlin es_Jan2010.pdf. Accessed on January 21, 2014.

10. Abideen PS, Chandrasekaran K, Maheswaran U, Vijayakumar A, Kalaiselvan. Implementation of Self Reporting Pharmacovigilance in Anti Tubercular Therapy Using Knowledge Based Approach. J Pharmacovigilance. 2013;1:101.

11. Mishin Vasil'eva IA, Makieva VG, Kuz'mina NV, Prikazchikova AV, Khoroshutina VV. Frequency pattern and diagnosis of adverse reactions in patients with pulmonary tuberculosis during chemotherapy with leading drugs. Probl Tuberk Bolezn Legk. 2003;7;24-09.

12. Dhingra VK, Rajpal S, Aggarwal N, Aggarwal JK, Shadab K, Jain SK. Adverse drug reactions observed during DOTS. J Commun Dis. 2004;36(4):251-9.

13. Anupa KC, Archana S, Sharath CV, Subish P, Pranaya M, Pathiyil RS. A study of adverse drug reactions caused by first line anti tubercular drugs used in directly observed treatment, short course (DOTS) therapy in western Nepal, Pokhara. J Pak Med Assoc. 2008;58:531-6.

14. Hema NG, Bhuva KB, Virupaksha HM. Critical assessment of adverse drug reactions to antitubercular drugs in a government teaching hospital. IJBMS. 2014;5(3).

Cite this article as: Revanna S, Harish CK, Gramle A. Adverse drug reaction monitoring of antitubercular drugs at tertiary care medical college hospital: prospective study. Int J Basic Clin Pharmacol 2017;6:2738-42. 